\title{
Surface-initiated ARGET ATRP of Poly(Glycidyl Methacrylate) from Carbon Nanotubes via Bioinspired Catechol Chemistry for Efficient Adsorption of Uranium Ions
}

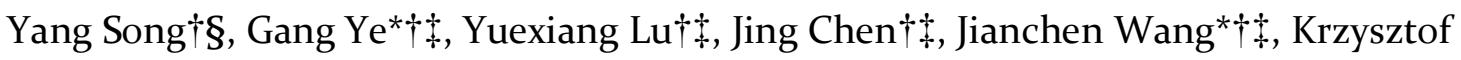 \\ Matyjaszewski*§ \\ $\uparrow$ Collaborative Innovation Center of Advanced Nuclear Energy Technology, Institute of Nuclear and New \\ Energy Technology, Tsinghua University, Beijing, 100084, China \\ \$ Beijing Key Lab of Radioactive Waste Treatment, Tsinghua University, Beijing 100084, China \\ $\S$ Department of Chemistry, Carnegie Mellon University, 440o Fifth Avenue, Pittsburgh, Pennsylvania \\ 15213, United States
}




\section{Experimental}

\subsection{Materials}

CNTs (diameter: 10 20 nm) commercially available (Nanjing Jicang Nanotechnology Co. LLC.) were treated with $3 \mathrm{M} \mathrm{HCl}$ aqueous solution at $60{ }^{\circ} \mathrm{C}$ for $3 \mathrm{~h}$. Dopamine hydrochloride ( 98\%) and tris(hydroxymethyl)aminomethane (Tris base, 99.5\%) were supplied by J\&K Scientific. Triethylamine (TEA, $\geq 99 \%$ ), $\alpha$-bromoisobutyryl bromide (BiBB, $\geq 98 \%$ ), copper dichloride $\left(\mathrm{CuCl}_{2}\right.$, 99\%), N,N,N',N",N"-pentamethyldiethylenetriamine (PMDETA, 99\%) and L-Ascorbic acid (reagent grade, crystalline) were purchased from Sigma-Aldrich. Glycidyl methacrylate (GMA, 97\%) was obtained from Aldrich and purified by passage through a neutral alumina column every time before use. Other analytical grade chemicals were commercially obtained and used with no further treatment. Deionized water (resistivity $>18 \mathrm{M} \Omega$ ) was obtained from a Milli-Q water purification system.

\subsection{Characterizations}

Transmission electron microscope (TEM) (HT-7700, Hitachi Ltd. Tokyo, Japan) at an accelerating voltage of $80 \mathrm{kV}$ was carried out for characterizing the structure of CNT and its composites. Functional groups were studied by Nicolet Nexus 470 Fourier Transform Infrared Spectroscopy (FT-IR) spectrometer with $\mathrm{KBr}$ matrix in the range $4000-400 \mathrm{~cm}^{-1}$. X-ray photoelectron spectroscopy (XPS) (PHI Quantera SXM spectrometer) with a monochromatic Al K $\alpha$ X-ray source was used to characterize the surface chemistry and element contents of CNTs and its composites. The photo-excited electrons were analyzed in CAE mode with pass energy of $100 \mathrm{eV}$ for the survey spectra and $30 \mathrm{eV}$ for the high resolution core level spectra. Data analysis and all envelopes of core level spectra were peak-fitted with a Lorentzian-Gaussian convoluted function (20/80) and a Shirley's background by the XPSPEAK software. Thermo-gravimetric analysis (TGA) was conducted on a SDT (Simultaneous DSC and TGA) Q600, TA Instruments, with the heating from rt. to $800{ }^{\circ} \mathrm{C}$ at a rate of $10^{\circ} \mathrm{C} \cdot \mathrm{min}^{-1}$ under nitrogen atmosphere.

\subsection{Preparation of polydopamine (PDA) coated CNTs}

CNTs were first modified by the deposition of a polydopamine layer using a recent reported method. ${ }^{1}$ $100 \mathrm{mg}$ CNTs was added into a solution containing $40 \mathrm{~mL}$ ethanol and $30 \mathrm{~mL}$ water, followed by ultrasonic dispersion for $10 \mathrm{~min}$. Then, $80 \mathrm{mg}$ dopamine hydrochloride was added under magnetic stirring. After $5 \mathrm{~min}, 20 \mathrm{~mL} 25 \mathrm{mM}$ Tris buffer solution was added dropwise by a constant pressure 
funnel. The reaction was kept at $25^{\circ} \mathrm{C}$ for $24 \mathrm{~h}$ then the product was washed with ethanol 3 times and separated by centrifugation. The product was stored in a vacuum oven at $60{ }^{\circ} \mathrm{C}$ for $24 \mathrm{~h}$. The CNTs-PDA were obtained as a black powder.

\subsection{Preparation of CNTs-PDA-BiBB macroinitiator}

CNTs-PDA (20 mg) was dispersed in $20 \mathrm{~mL}$ DMF and treated by ultrasonication for $10 \mathrm{~min}$. Then, under $\mathrm{N}_{2}$ protection and magnetic stirring, $1 \mathrm{~mL}$ TEA $(7.2 \mathrm{mmol})$ was added dropwise. After a further10 min, a pre-mixed solution of $0.9 \mathrm{~mL} \mathrm{BiBB}(7.2 \mathrm{mmol})$ in $10 \mathrm{~mL}$ DMF, was added by a constant pressure funnel. The reaction was stirred under continuous $\mathrm{N}_{2}$ presence for $24 \mathrm{~h}$ at $25{ }^{\circ} \mathrm{C}$. The mixture was repeatedly washed with acetone, ethanol and water, respectively. Then, the product (CNTs-PDA-BiBB) was placed in a vacuum oven at $60^{\circ} \mathrm{C}$ for $24 \mathrm{~h}$.

\subsection{ARGET ATRP growth of PGMA brushes}

First, CNTs-PDA-BiBB (10 mg, $0.015 \mathrm{~mol}$ initiator) was mixed with $2 \mathrm{~mL}$ methanol/DMF/anisole in a small vial, followed by ultrasonic treatment for $30 \mathrm{~min}$. Then, $1.7 \mathrm{~g}$ purified GMA ( $\sim 12 \mathrm{mmol}), 2$ $\mathrm{mL} \mathrm{CuCl}_{2}$-PMDETA stock solution (containing $0.0036 \mathrm{mmol} \mathrm{CuCl}_{2}$ and $0.036 \mathrm{mmol}$ PMDETA) were added sequentially under magnetic stirring. After that, the vial was sealed with a rubber plug and degassed by $\mathrm{N}_{2}$ purging. After $10 \mathrm{~min}$, a solution of $15 \mathrm{mg}$ ascorbic acid $(0.084 \mathrm{mmol})$ in $1 \mathrm{~mL}$ methanol/DMF/anisole was added via a syringe. The molar ratio of the reagents was monomer: macroinitiator: catalyst: ligand: reducing agent $=800: 1: 0.24: 2.4: 5.6$. The reaction was kept at $25{ }^{\circ} \mathrm{C}$ for $4 \mathrm{~h}$. Then, the product was successively washed with $\mathrm{CH}_{2} \mathrm{Cl}_{2}$, ethanol and water. The CNTs-PDA-PGMA products were dried in a vacuum oven at $60^{\circ} \mathrm{C}$ for $24 \mathrm{~h}$.

\subsection{EDA functionalization of CNTs-PDA-PGMA}

CNTs-PDA-PGMA (10 mg) synthesized in methanol was added to a $25 \mathrm{~mL}$ flask, followed by the addition of $5 \mathrm{~mL}$ EDA. Under stirring and $\mathrm{N}_{2}$ protection, the reaction heated to $80{ }^{\circ} \mathrm{C}$ for $5 \mathrm{~h}$. Finally, the product was separated and washed with ethanol and water. The obtained CNTs-PDA-PGMA-EDA was dried under vacuum at $60{ }^{\circ} \mathrm{C}$ for at least $24 \mathrm{~h}$ before used for uranium adsorption study.

\subsection{Uranium adsorption experiment}

Adsorption of $\mathrm{U}(\mathrm{VI})$ onto the functionalized CNTs was carried out by batch operations. The initial $\mathrm{U}(\mathrm{VI})$ solutions $\left(50 \mathrm{mg} \mathrm{L}^{-1}\right)$ were prepared by diluting concentrated $\mathrm{U}(\mathrm{VI})$ stock solution $\left(200 \mathrm{~g} \mathrm{~L}^{-1}\right)$. $\mathrm{pH}$ values were adjusted to 5 by addition of $\mathrm{NaOH}$ solution and calibrated by a PHS-3C model meter. 
Adsorption experiments were performed at $301 \mathrm{~K}$ with $0.25 \mathrm{~g} \mathrm{~L}^{-1}$ phase ratio and contact time of 24 $\mathrm{h}$. Then, the aqueous phase was separated by using a $0.45 \mu \mathrm{m}$ micro-pore filter. U(VI) concentration was measured by the arsenazo III method with a 721 type spectrophotometer at $650 \mathrm{~nm}$.

Adsorption capacity $Q$ is defined as:

$$
Q=\frac{\left(C_{0}-C_{\mathrm{t}}\right) \times V}{M}
$$

and removal ratio $\mathrm{R}$ is defined as:

$$
R=\frac{\left(C_{0}-C_{\mathrm{t}}\right)}{C_{0}} \times 100 \%
$$

where $C_{0}$ and $C_{\mathrm{t}}$ are the initial and residual $\mathrm{U}(\mathrm{VI})$ concentration in aqueous solution, respectively. $V$ is the volume of the initial solution and $M$ is the weight of the engaged adsorbent. 


\section{Results and discussion}

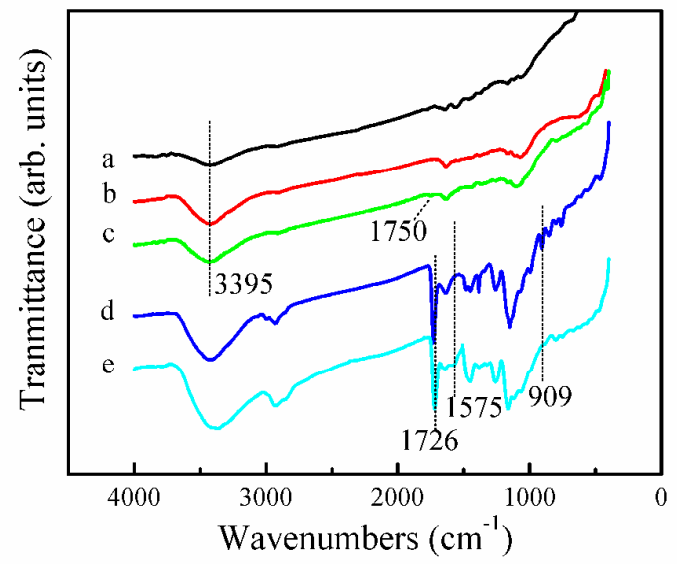

Figure S1. FT-IR spectra of (a) CNTs; (b) CNTs-PDA; (c) CNTs-PDA-BiBB; (d) CNTs-PDA-PGMA; (e) CNTs-PDA-PGMA-EDA. 


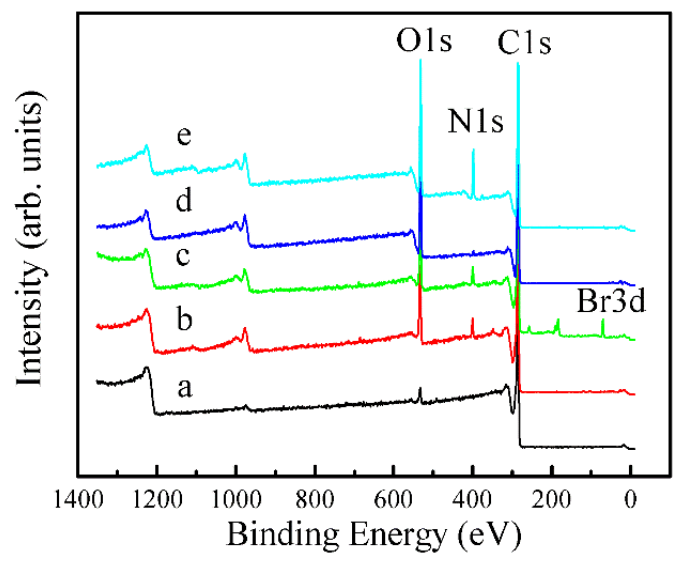

Figure S2. XPS survey spectra of (a) CNTs; (b) CNTs-PDA; (c) CNTs-PDA-BiBB; (d) CNTs-PDA-PGMA; (e) CNTs-PDA-PGMA-EDA.

Table S1 Element content analysis of the functionalized CNTs by XPS.

\begin{tabular}{lcccc}
\hline \multirow{2}{*}{ Samples } & \multicolumn{5}{c}{ XPS (atomic \%) } \\
\cline { 2 - 5 } & $\mathrm{C}$ & $\mathrm{O}$ & $\mathrm{N}$ & $\mathrm{Br}$ \\
\hline CNTs & 97.4 & 2.4 & 0.2 & 0.0 \\
CNTs-PDA & 86.9 & 9.6 & 3.0 & 0.0 \\
CNTs-PDA-BiBB & 82.4 & 10.9 & 4.6 & 2.1 \\
CNTs-PDA-PGMA & 75.5 & 23.2 & 1.2 & 0.1 \\
CNTs-PDA-PGMA-EDA & 68.7 & 19.7 & 11.4 & 0.2 \\
\hline
\end{tabular}




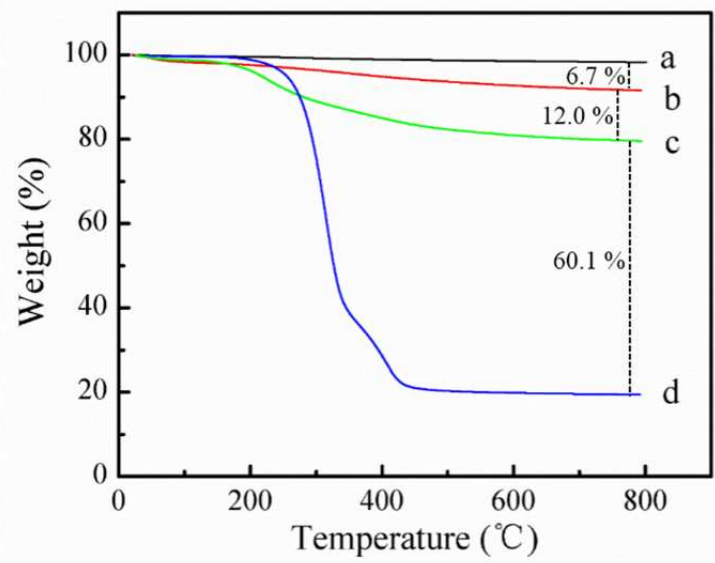

Figure S3. TGA curves of (a) CNTs; (b) CNTs-PDA; (c) CNTs-PDA-BiBB; (d) CNTs-PDA-PGMA.

By comparing the TGA curves of pristine CNTs and CNTs-PDA (Figure S3), it can be estimated that approximately $6.7 \mathrm{wt} \%$ of dopamine is deposited onto the pristine CNTs. Furthermore, approximately $12.0 \mathrm{wt} \%$ of $\mathrm{BiBB}$ is immobilized to CNTs-PDA, while $60.1 \mathrm{wt} \%$ of PGMA is grafted from the surface of CNTs-PDA-BiBB. Therefore, TGA analysis confirms that a remarkable amount of PGMA brushes are grown on the surface of CNTs. 


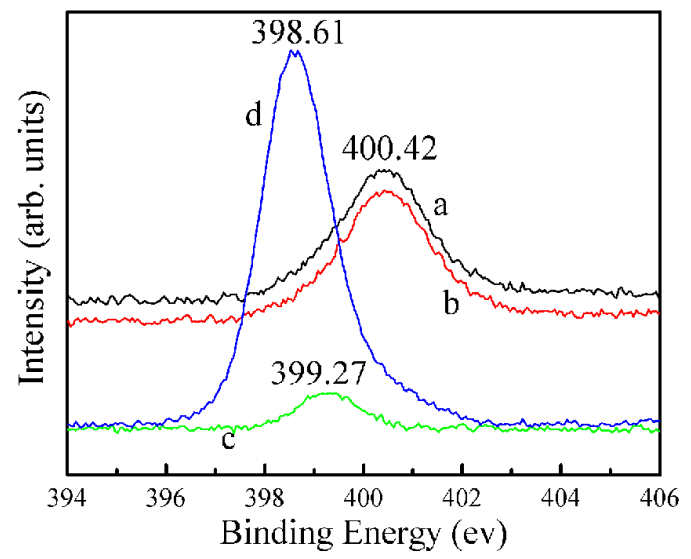

Figure S4. High resolution N1s XPS spectra of (a) CNTs-PDA; (b) CNTs-PDA-BiBB; (c) CNTs-PDA-PGMA; (d) CNTs-PDA-PGMA-EDA. 

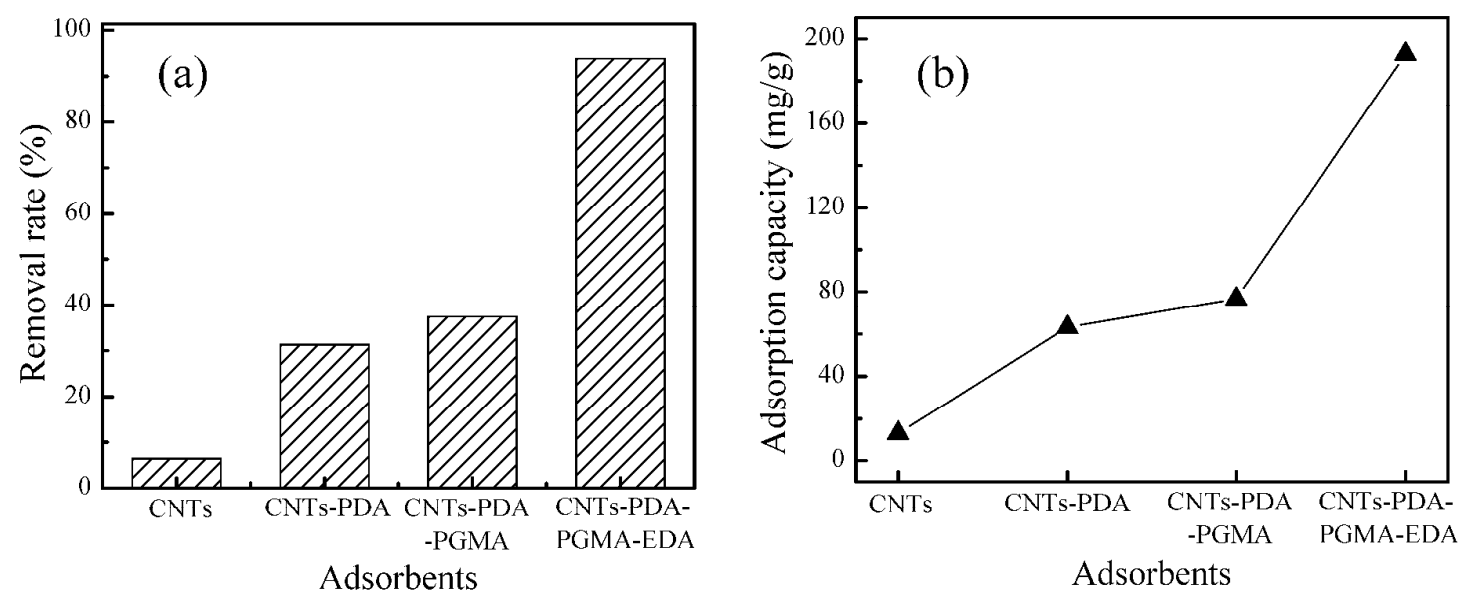

Figure S5. Uranium removal rate (a) and adsorption capacity (b) of the functionalized CNTs. 


\section{Reference}

(1) Yue, Q.; Wang, M.; Sun, Z.; Wang, C.; Wang, C.; Deng, Y.; Zhao, D. J. Mater. Chem. B 2013, 1, 6085. 